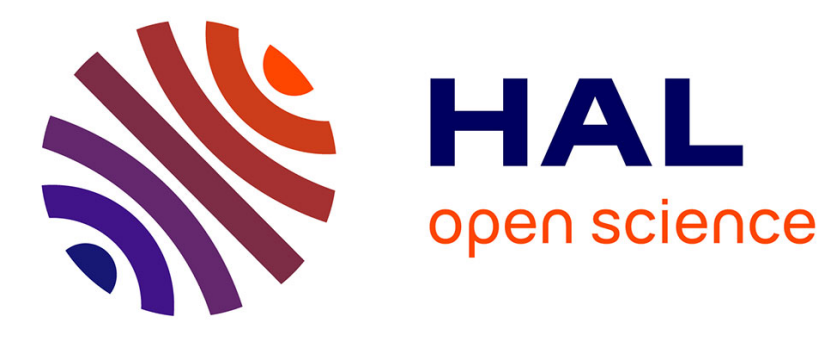

\title{
PV Integration by Building Energy Management
}

Rim Missaoui, Ghaith Warkozek, Seddik Bacha, Stéphane Ploix

\section{To cite this version:}

Rim Missaoui, Ghaith Warkozek, Seddik Bacha, Stéphane Ploix. PV Integration by Building Energy Management. III International Conference on Power Engineering, Energy and Electrical Drives (IEEE POWERENG 2011), May 2011, Malaga, Spain. 10.1109/PowerEng.2011.6036453 . hal-00593911

\section{HAL Id: hal-00593911 \\ https://hal.science/hal-00593911}

Submitted on 18 May 2011

HAL is a multi-disciplinary open access archive for the deposit and dissemination of scientific research documents, whether they are published or not. The documents may come from teaching and research institutions in France or abroad, or from public or private research centers.
L'archive ouverte pluridisciplinaire HAL, est destinée au dépôt et à la diffusion de documents scientifiques de niveau recherche, publiés ou non, émanant des établissements d'enseignement et de recherche français ou étrangers, des laboratoires publics ou privés. 


\title{
PV Integration by Building Energy Management System
}

\author{
Rim.Missaoui ${ }^{1}$, Ghaith.Warkozek ${ }^{1}$, Seddik. Bacha ${ }^{1}$, Stéphane.Ploix ${ }^{2}$. \\ ${ }^{1}$ G2LAB Grenoble Electrical Engineering laboratory \\ ${ }^{2}$ G-SCOP Grenoble Sciences of Conception, \\ Optimization and Production \\ University of Grenoble \\ Email: rim.missaoui@ @g2eLab.grenoble-inp.fr
}

\begin{abstract}
This paper focuses on Energy Management System (EMS) applied to the residential sector. The EMS architecture is proposed. It is composed on three layers: anticipation, reactive and device (local) layers. However, to validate global control algorithms, a simulator capable of interoperating with energy management systems must be used. This work presents a solution for real-time simulation with a networked system that manages energy flows. It makes it possible to perform fine simulations of the physics, including fast dynamics of electrical appliances imbedded on the buildings. This paper deals with computing the starting times of some services in one hand and in determining set points of others on other hand; the maximal power constraints and predicted events are taken into account. A Satisfaction Problem formulation has been proposed. So, the purpose is to maximize user comfort and minimize energy costs. An application example is presented.
\end{abstract}

\section{NOMENCLATURE}

$i$

$k$

$\Delta$

$E_{p v}(k)$

$E_{\text {cons }}(k)$

$E(i, k)$

$E_{p}(i, k)$

$E_{S}$

$P_{p v}(k)$

$P_{\text {sol }}(k)$

$P_{i}$

$\rho<1$

S

$\tau_{\mathrm{CO}_{2}}(i, k)$

$C_{\text {tot }}$

$C_{\text {auto }}$

$C_{\text {bought }}$

$C_{\text {sol }}$
Sampling step time, [second].

The service $i$.

The number of period Period.

Sampling time of the anticipatory layer.

Energy produced locally by the $\mathrm{PV}[\mathrm{kWh}]$.

Total energy consumed by the load [kWh].

Energy consumed by the service i

during

period $\mathrm{k}$ [kWh].

Energy produced by the source i during period $\mathrm{k}[\mathrm{kWh}]$.

Consumed energy by the shiftable service $[\mathrm{kWh}]$.

PV power produced locally [W].

Solar radiation energy [W].

The average power consumed by the service the period $\Delta k$. [W].

Efficiency of the PV installation.

Capture area of radiation $\left(\mathrm{m}^{2}\right)$

Is the volume of $\mathrm{CO} 2$ emitted during the period $\mathrm{k}$.

Total cost of the system ( $€ / \mathrm{kWh})$.

Self consumption price $(€ / \mathrm{kWh})$.

Bought energy price (€/kWh).

Purchasing price for PV production injected to network, ( $€ / \mathrm{kWh})$.

Total comfort criterion.

$y(i, k) \quad$ comfort criterion of each service i during

periode $\mathrm{k}$.

$J_{e c g} \quad$ Ecological criterion.

$T_{\text {out }} \quad$ The temperature outsiede the room [K].

$T_{\text {in }} \quad$ Instantaneous temperature in the room $\mathrm{i}$

$[\mathrm{K}]$.

$T_{m} \quad$ The temperature outsiede the room [K].

$T_{o p} \quad$ The optimum heating temperature [K].

$K_{\text {heater }}, K_{\text {sun }}, \tau: \quad$ Constants.

$\Phi_{\text {heater }}$

$\Phi_{\text {sun }}$

Heat flux given by the radiator.

Heat flux of sunlight through the window.

Air Heat capacity of the room i [J / K].

$c_{i}$

$c_{m}$

Envelope heat capacity of the room[J /

$\mathrm{K}]$.

$S F$

RST

$R_{i}$

$a_{1} \ldots a_{4} ; b_{1} \ldots b_{4}$

$f(i)$

$\Phi_{\text {opt }}$

$s(i)$

$P_{a}$

$y_{(.)}(i, k)$

Window Area $\left[\mathrm{m}^{2}\right]$.

Washing machine requested starting time.

The equivalent total thermal resistance between the room and outdoors.

Constants.

The end effective date of the operating cycle of the shiftable service.

End date desired by the user of the shiftable service.

Effective execution date of the shiftable service.

This variable stands for any variable that could be PV, grid power, or load power if calculation is valid for all of them.

This variable stands for any service that could be hearting service or washing machine.

\section{INTRODUCTION}

A

HOME automation system basically consists of household appliances linked via a communication network allowing interactions for control purposes [1]. 
Thanks to this network, a load management mechanism can be carried out: it is called distributed control in [2]. Since then, several studies have been conducted in order to design an optimized electric energy management system able to determine the best energy assignment plan, according to given criteria. In [3], analyzes of the load management techniques are well defined in great detail. [4] presents the design of a generic Energy Management System, which is scalable to any application requiring management of energy acquisition from multiple energy sources, energy delivery to multiple energy users and storage of excess energy in one or more storage devices. According to [5], EMS contains methods that coordinate the activities of energy consumers and energy providers in order to best fit energy production capabilities with consumer needs and, in this way, avoiding energy demand peaks, which generally have adverse environmental impacts and increase energy production costs.

In this context, an energy management system (EMS) has been developed; it is composed by three control layers [6][7]. These layers are composed by: an equipment layer, with local and fast control mechanism, a reactive layer, which is triggered when energy constraints are violated, and an anticipative layer, which adjusts future set-points of appliances in order to tackle energy events that can be foreseen.

The electric architecture is given in "Fig.1", representing the duality sources/loads in the presence of PV generation and Grid connection. The electric system is managed by a three layers control system (Expert and Predictive). This architecture facilitates the energy flow management between components. The building can be supplied by any source or combination of sources. The possibility to reschedule some controllable loads in the day gives a more flexible control for system.

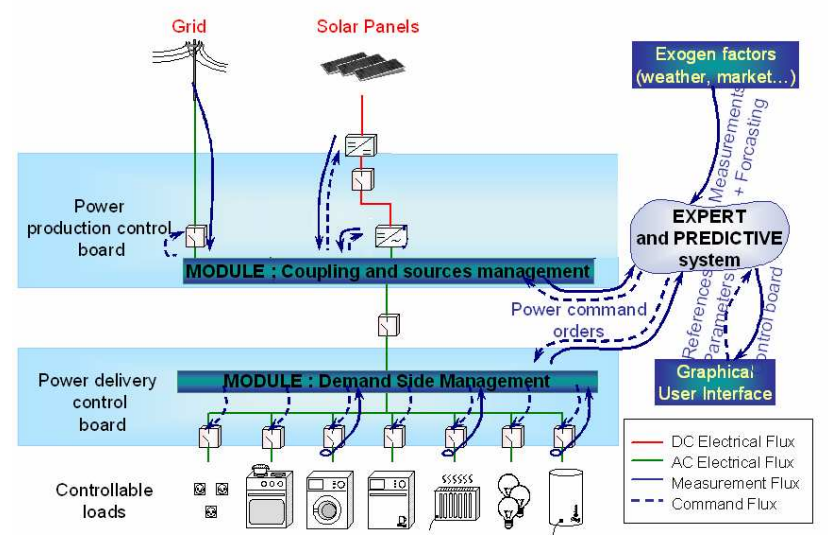

Fig 1: Muti-sources system and sources and loads co-management system architecture.

The rest of the paper is organized as follows. The section II is devoted to the description of the EMS architecture, which consists of three control layers. Section III deals with the validation issue of EMS and gives a proposed solution: validation through real time simulation. In section IV, a application example is modeled. A case of study giving some simulation models for building is proposed in section V. At the end of this last section results are presented.

\section{ARCHITECTURE OF THE EMS.}

An important issue in the problems of home automation is the uncertainty in the models and in the predicted data such as solar radiation, temperature or services requested by the occupants. To solve this problem, three-layer architecture is presented in "Fig.2" (see [8]): a layer of anticipation, a reactive layer and a local layer.

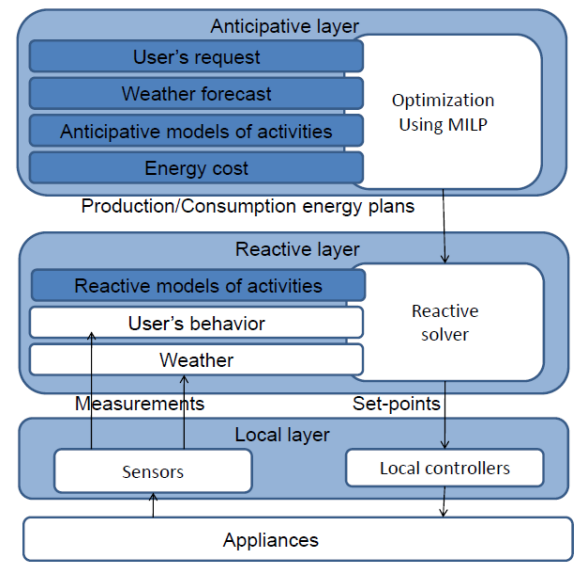

Fig.2: The multi-layer system of power management.

\section{A. Anticipation mechanism:}

The anticipation layer includes control that operates on average quantities associated with long periods of time (typically 1 hour) in the EMS. Its objective is to plan production and consumption of energy over long time covering typically one day. The prediction is based on weather forecasts and on user programming for appliances.

If consumption of all facilities can be anticipated, it is possible to plan and schedule their operations in advance. For example, for an electric heating service of a room, we can calculate the duration and the amount of overheating "anticipated" which will reduce the consumption during a period where power is unavailable, restricted or more expensive. For the case of a time-shifted service such as the service provided by a washing machine for example, we can delay or advance its start to shape the overall consumption [9].

\section{B. Reactive mechanism:}

Because the anticipation mechanism works with average values over relatively long periods on the basis of predicting energy needs, a finer level to respond to disturbance (modelling errors and errors of prediction) is necessary. This level operates with a short period of time (typically 1 minute) comparing to the anticipation layer in order to meet the criterion of comfort for the occupants and the capacity constraints of energy sources. Practically, if the actual situation deviates too much from the anticipation plan and exceeds energy resources for example, the reactive layer will respond by shedding the consumption of certain appliances in order to satisfy feasible energy balances. Since the time scale 
is small compared to the proactive mechanism, adjustments calculated by the reactive layer remain negligible for the proactive layer which only calculates average values if the predictions were consistent with the actual situation [10].

\section{Device mechanism:}

This control layer is the one with the fastest dynamics. Its goal is to apply set points, computed by the anticipation layer and possibly adjusted by the reactive layer. For example, in a thermal environment, this mechanism aims at maintaining the temperature to values close to temperature set points temperature. This mechanism is provided by appliance manufacturers and not modified.

Such an EMS must be validated on a fine simulation tool because the algorithms for managing energy flows are based on simplified models. This work presents a methodology used for these fine system simulations. Initially, we modelled a multi-source and multi-loads home to validate the global control algorithm. The modelling has been done in the MATLAB / Simulink environment supplemented by a specific real-time library [11].

\section{VALIDATION TOOL OF EMS.}

To validate the EMS by a fine simulation, some problems have been encountered. The EMS and the physical simulator use different solving platform. For instance, the EMS is a Java application coupled with solvers whereas the simulator is not available in Java. For this purpose, models in MATLAB/Simulink, TRANSYS [12], Energy+..., are usually used. The second problem is the synchronization of the EMS with the physical simulator. Indeed, accelerated time requires shared clocks. The fine simulation is based on detailed physical models, hence the need for a large enough computing power, which is not necessary for EMS. Therefore, in this work, architectural solution is proposed "Fig3". The EMS is interfaced with the simulation model running on real-time platform (RT_LAB [11]) with Ethernet communication.

A real time simulator has been chosen for the following reasons:

- Validation can be done before the building construction because the sizing of some appliances (like HVAC systems) depends on the results: the simulation of some typical days has to be done during the design phase

- Reference results are needed because with actual building systems, sensors are usually not properly calibrated and data may be not accurate. A reference simulation of what the results should be is useful.

- Among the sensors, some have to be used for the power management and some others only for the validation. Validating on an actual building requires design of communication interfaces for validating sensors. It is usually a difficult task because of the diversity of communication technologies and, in addition, some sensors may not have communication interfaces. Detailed validations with lots of available data and an in-situ validation with less available data is much easier to tackle.

The test environment in "Fig3" consists of two computers and the real-time simulator RT_LAB. The first computer is used to design simulation models of a building system and also to visualize simulation results (see section $\mathrm{V}$ ). The second computer is a control station which is dedicated to the EMS where the communications is handled via the TCP/IP protocol (see section IV).

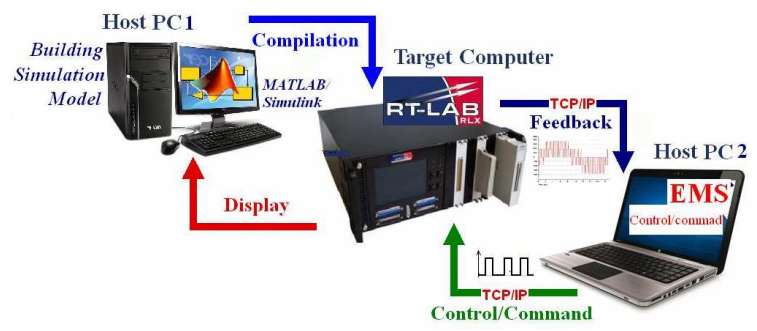

Fig.3: Conceptual schema of a Real Time platform

The EMS must be able to act on the simulator. A communication tunnel has been developed to transfer the commands of the EMS to the simulated models (under RT_LAB), and to transfer the state variables of the simulated models to the EMS.

To achieve this goal, the architecture shown in [13] is designed to establish a socket for each model (service), then to take orders and measurements via this socket. Each service simulated in RT_LAB has a counterpart in the energy management system; correspondence is done by the port number of each socket. This package has been developed in Java.

\section{MODELING PROBLEM IN EMS}

\section{A. Scheduling problem of production and consumption of energy.}

For the optimization problem of energy flows, a ressource assignment plan is defined by the anticipation layer [10]. It is calculated using a set of methods to coordinate the activities of consumption and energy production to optimize the cost, comfort and ecology criterion, satisfying the constraints of the system. The consumed energy $E(i, k)$ for each service $i$ during each period $k$, is calculated to optimize the criteria detailed below.

\section{- Economic criterion:}

$$
\begin{aligned}
& C_{\text {tot }}=-C_{\text {auto }} \min \left(E_{P V} ; E_{\text {cons }}\right)+C_{\text {bought }} \max \left(E_{\text {cons }}-E_{P V} ; 0\right) \\
& -C_{\text {sold }} \max \left(E_{P V}-E_{\text {cons }} ; 0\right) .
\end{aligned}
$$

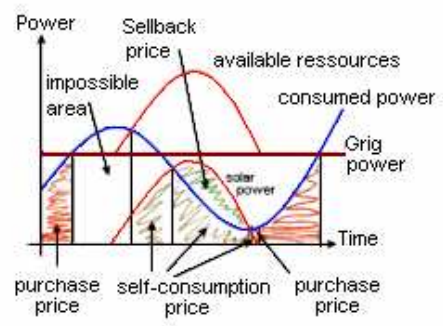

Fig 4: Strategy of energy purchasing 
- Comfort criterion: $J_{\text {comf }}(i)=\sum_{k=1}^{K} y(i, k)$

- Ecological criterion: $J_{e c g}=\tau_{\mathrm{CO}_{2}}(i, k) \times E_{p}(i, k)$

The problem of energy management is a problem of optimizing multi-criteria whose criteria are contradictory. A solution satisfying all the constraints of systems must be determined and a best compromise between the different criteria must be achieved.

Sources and load co-management used in the EMS are formulated as Mixed Integer Linear program MILP [6]-[5]. The problem is formulated and implemented in Java. In this paper, we present just the mathematical formulations models before the linearization, and then the equations of energy optimization are presented.

\section{B. Control model.}

The anticipation anticipative layer computes the production and consumption plans. These calculations are carried out based on the general model of the PV system integrated to the grid via the host building. The grid can be considered theoretically as a permanent power source with a given voltage and frequency. It is possible to exchange the total PV production or its surplus according to energy purchasing and selling policy. It is possible to predict the average production capacity (by using statistical and forecasted data) over an interval of discretization (a step of 1 hour). Notice that the storage system is not taken into consideration here.

In general, loads in buildings are composed of non controllable and controllable devices. By non controllable, we mean autonomous devices like freezer and by controllable we mean systems, which can be delayed or dispatchable: cooking machine, heaters.... In this paper, we considered only the controllable loads, which are defined as power consumption of medium consequence and flexible scheduling that can be rescheduled to other times of the day (likely washing machine, dryers, and hot water heaters etc.).

The anticipation layer makes plans for energy allocations; which it consists in determining both the starting dates of the timed services, and the set points of the permanent services mainly composed of HVAC systems of which the set-points correspond to temperatures.

\section{1) Set point Temperature:}

Anticipation requires a relevant thermal air environment model to predict the consumption of HVAC system. Because of the importance of uncertainties in predictions, the simple thermal dynamic model presented in [14] has been preferred:

$$
c_{i} \frac{d T_{\text {in }}(t)}{d t}=P_{i}(t)-\frac{1}{R_{i}}\left(T_{\text {in }}(t)-T_{\text {out }}(t)\right)
$$

$P i$ stands for the average thermal power provided by the heater during the period $\Delta \mathrm{k}$.
In order to define the set point temperature for each anticipative periode $\Delta \mathrm{k}$, the anticipative layer calculates the thermal satisfaction as a function of temperature as folow:

$y_{T}(i, k)=\left\{\begin{array}{lll}a_{1} T_{i n}(i, k)+b_{1} & \text { if } & T_{\text {in }}(i, k) \leq T_{\text {opt }} \\ a_{2} T_{\text {in }}(i, k)+b_{2} & \text { if } & T_{\text {in }}(i, k) \geq T_{\text {opt }}\end{array}\right.$

2) Starting date of timed services:

A timed service is modelled as an on/off service. Its consumption during a period $\Delta \mathrm{k}$ is then modeled by $E_{S}(i, k) \in\left\{0, \Delta x P_{i}\right\}$ where $P i$ characterizes the average power consumption of the service. It is possible to shift this service in a time range to search for an optimal execution date according to the optimization criteria [8].

$$
E_{S}(i, k)= \begin{cases}E^{\prime}(i, k)=(\operatorname{Min}[f(i),(k+1) \Delta]- \\ \operatorname{Max}[s(i), k \Delta]) P(i) & \text { if } \quad E^{\prime}(i, k)>0 \\ 0 & \text { if } \quad E^{\prime}(i, k) \leq 0\end{cases}
$$

When the energy source is sufficient for all the timed services requesting energy, the starting time $s(i)$ is equal to the requested starting time $R S T(i)$. Nevertheless, an issue appears when the available energy is not sufficient for all. Some services must be delayed or executed sooner, it means the actual starting time $s(i) \neq R S T(i)$, and this effect decreases the user comfort but may increases the economic criterion. The comfort criterion is expressed as follows:

$$
y_{S}(i)=\left\{\begin{array}{lll}
1 & \text { if } & s(i)=R S T(i) \\
a_{3} s(i)+b_{3} & \text { if } & s(i)<R S T(i) \\
a_{4} s(i)+b_{4} & \text { if } & s(i)>R S T(i)
\end{array}\right.
$$

Total of energy consumed by loads for one period $\mathrm{k}$.

$$
E_{\text {cons }}=\sum_{i} E(i, k)
$$

\section{Optimization problem.}

The EMS is a multi-objectives optimization, where the anticipation control layer tries to maximize the total satisfaction of services:

$$
\text { Maximize } \sum_{k=1}^{K} y_{(.)}(i, k)
$$

And, at the same time, to minimize the total energy cost

$$
\text { Minimize } C_{\text {tot }}
$$

Global criterion is a compromise between comfort and cost. The criterion that results from the aggregation of two types of criteria: economic criterion determined by the total cost of energy and comfort criterion function of the thermal sensation of the heating services and the shifting of timing services are:

$$
J=(\underbrace{\sum_{k=1}^{K}\left(C_{\text {tot }}(k)\right.}_{\text {Economic citerion }}-\underbrace{\left.\sum_{i=1}^{I} y_{(.)}(i, k)\right)}_{\text {Comfort criterion }})
$$

Two scenarios can be used here. For instance, the first one when the energy cost may be set and be considered as a 
constraint. For example, consider an economic mode where inhabitants accept to decrease the comfort level in order to reduce the energy bill. In the second scenario, the comfortable mode is preferred by the EMS, which amounts to search a solution based only on the comfort criterion. So, the EMS system then selects the best solutions based on the preferences of the consumer.

As it is mentioned in section II, reactive management actions can be carried out preferably in following order:

- respect as well as possible the anticipative plan defined by the anticipative layer, the assigned energy for each device is equal to the value pre-defined by the anticipative plan. Whenever an unpredicted event occurs, it is important for the system to re-assign immediately the energy to satisfy the demand. Then, a new operation plan needs to be computed by the anticipative layer:

$$
\text { Minimize } J=(\underbrace{\sum_{k=\theta}^{K}\left(C_{\text {tot }}(k)\right.}_{\text {Economic citerion }}-\underbrace{\left.\sum_{i=1}^{I} y_{(.)}(i, k)\right)}_{\text {Comfort criterion }})
$$

where $\theta$ is the beginning of unpredicted event.

The initial conditions are the values of variables obtained at $(\theta-1)$

\section{CASE OF STUdY: SiMULATION MODEL FOR BUILDING}

To validate the precedent optimization approach, we modeled the building more finely on MATLAB / Simulink (Host PC1 see "Fig3"). This model contains the grid, the PV panel and three controllable loads: two modular loads (heating and fridge) and shiftable load (washing machine).

\section{A. Sources simulation model:}

The distribution network is modelled by a simple voltage source controlled by a switch-on current (limited to the value imposed by subscription). Regarding renewable source, the PV system is sized with $2 \mathrm{KW}$ peak. The power generated $P_{P V}$ is $\rho=10 \%$ of solar energy radiated $P_{\text {sol }}$ measured in real time based on weather data every 10 minutes from Grenoble (France). Hence the PV model is written as follow:

$$
P_{P V}=\rho . \text { S. } P_{\text {sol }}
$$

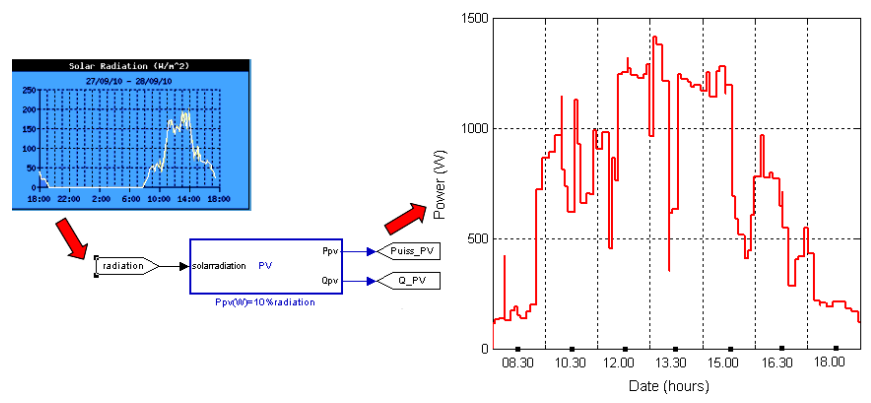

Fig5: MATLAB/Simulink PV simulation model.

\section{B. Loads simulation model:}

To illustrate the results of the optimization of energy flows in the building, we modify the behaviour of some electrical appliance.

TABLE I: LIST OF MODELLED EQUIPEMENT.

\begin{tabular}{lcl}
\hline \hline Name & Power max (kw) & \multicolumn{1}{c}{ Modelled as } \\
\hline Heating & 1.00 & permanent service \\
system unit & & \\
Fridge & 0.10 & permanent service \\
Washing & 2.40 & timed service \\
\hline \hline
\end{tabular}

\section{1) Heating simulation model:}

In this example, the heating service is provided by a single heater $1 \mathrm{KW}$. In the real case study, this service is provided by heaters in each room of the flat. The chosen model in [15] is finer than the model selected by the management system. This is a first order linearized model [8], whereas Simulink models are not linearized. In addition, they depend on several factors such as the structure (surfaces, heights, walls, insulation, windows, the outside temperature, the solar radiation...). This thermal model can be formulated as follows:

$\left[\begin{array}{c}\frac{d T_{\text {in }}}{d t} \\ \frac{d T_{m}}{d t}\end{array}\right]=\left[\begin{array}{cc}-\left(\frac{1}{r_{i} C_{i}}+\frac{1}{r_{m} C_{i}}\right) & \frac{1}{r_{m} C_{i}} \\ \frac{1}{r_{m} C_{m}} & -\frac{1}{r_{m} C_{m}}\end{array}\right]\left[\begin{array}{l}T_{\text {in }} \\ T_{m}\end{array}\right]+\left[\begin{array}{ccc}\frac{1}{r_{m} C_{i}} & \frac{1}{C_{i}} & \frac{S F}{C_{i}} \\ 0 & 0 & 0\end{array}\right]\left[\begin{array}{c}T_{\text {out }} \\ \Phi_{h} \\ \Phi_{s}\end{array}\right]$

\section{2) Fridge simulation model:}

The fridge and freezer are thermal services whose models are closed to the one of a room with heater except that the sun has no impact.

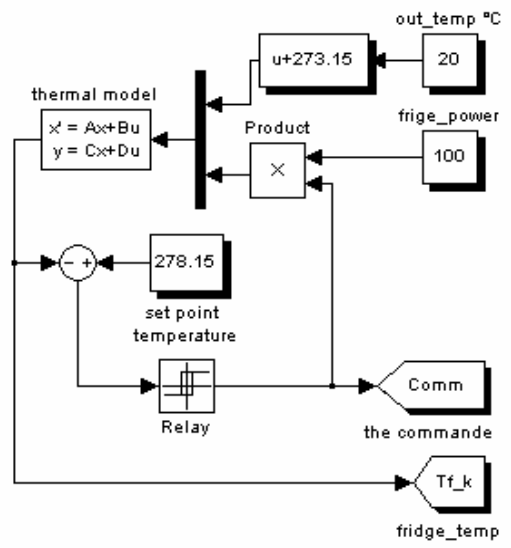

Fig 6: MATLAB/Simulink Fridge model;

\section{3) Washing machine simulation model:}

The behavior of the washing machine is modeled by three cycles whereas the model used by the EMS has a only one cycle operation (see Fig7) [16]. 

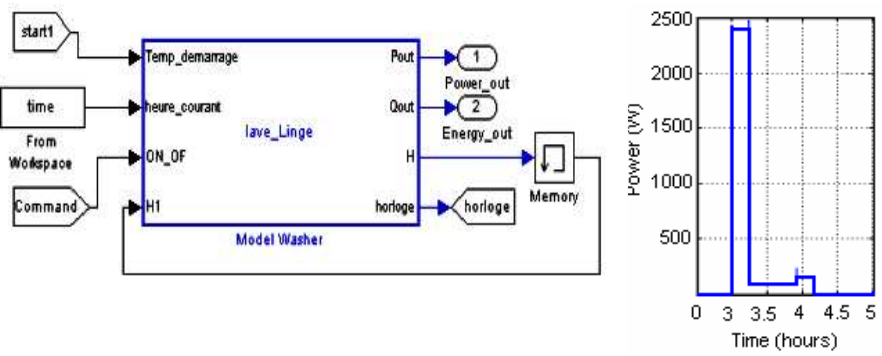

Fig 7: MATLAB/Simulink washing machine simulation model

TABLE II: ENERGY DISTRIBUTION AND THE AVERAGE LENGTH OF CYCLES

\begin{tabular}{lcc}
\hline \hline & Cycle time $(\mathrm{mn})$ & Power $(\mathrm{W})$ \\
\hline Temperature & $30 / 40^{\circ} \mathrm{C}$ & $* *$ \\
Cycle average length & 70 & $* *$ \\
Heating & 15 & 2400 \\
Washing and rinsing & 40 & 80 \\
Spinning & 15 & 150 \\
\hline \hline
\end{tabular}

\section{Simulation results:}

Let's consider a single room with a surface $S=20 \mathrm{~m}^{2}$. It is equipped with the list of devices given in table I. L'EMS must perform a plan to assign the energy resource 24 hours in advance for a time discretization of $\Delta=1$ hour. Data and control signals exchanged between the simulator and the EMS are summarized in "Fig. 8".

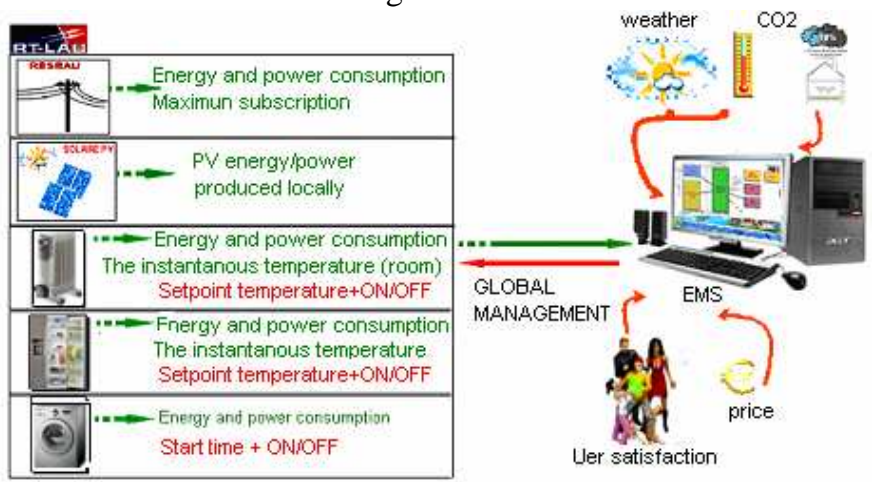

Fig 8: Exchanged command (red) from MS and data (green) from Simulator

According to data sent by the simulator, the EMS creates a problem then solves it. The optimum temperature for the heating service is $\mathrm{T}_{\mathrm{opt}}=20^{\circ} \mathrm{C}$. The requested start time of the washing mashine is RST=7:00 am. We set a purchase price of grid $\mathrm{C}_{\text {bought }}$ as "Fig.9":

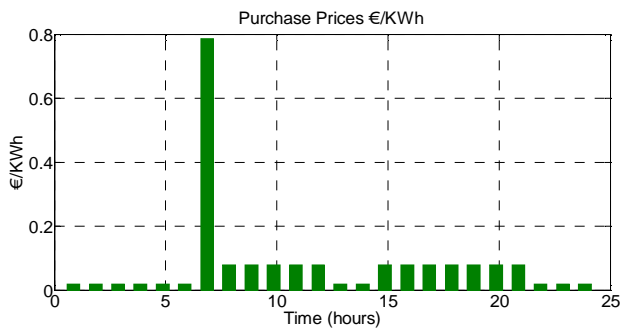

Fig 9: Purchase price of grid during 24 hours.

At [7:00 am, 8:00 am] the price is higher than the rest of the day $(0.787 € / \mathrm{KWh})$. The auto consumption price $\mathrm{C}_{\text {auto }}$ corresponding to German PV tariffs and the reselling price for $\mathrm{PV}$ production injected to grid $\mathrm{C}_{\text {sold }}$, are constant: $\mathrm{C}_{\text {auto }}=0.25 € / \mathrm{KWh}$ and $\mathrm{C}_{\text {sold }}=0.41 € / \mathrm{KWh}$.

\section{1) Case without EMS:}

In this case, there is no control of temperature set points of permanent services. We assumed that the occupants chose the starting time of the washing machine when the price is very high in the morning 7:00 am. This led of course to expensive consumption (2.5€) compared to the other prices during 24 hours.
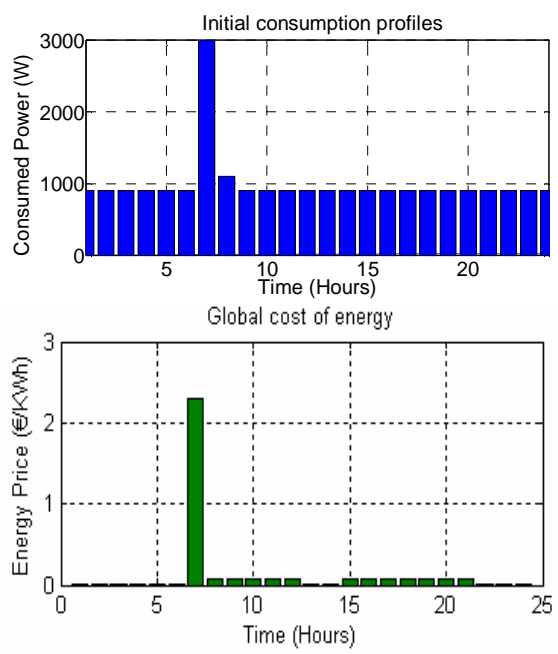

Fig 10: Scenario without management system

With this simple scenario, we show that, we can lose on the cost criterion "Fig 10", but we win on the comfort criterion because the RST is respected.

\section{2) Case with EMS:}

In the two cases of "Fig.11 (a-b)", the EMS shifted the starting of the washing machine from 7:00am to 9:00am. At this hour, $0.16 €$ is paid instead $2.5 €$ at 7:00am.

A PV system is integrated to the building assuming the German energy tariffs (re-selling surplus is authorised), the cost of the washing service is unchanged (about $0.16 €$ ) but the global cost for all the services is decreased. This is due to the surplus reselling (see Fig. 11-b)

The German energy policy gives preference to the local consumption, so we see that there is no consumption from the grid when there is enough production. In addition, when production exceeds consumption, surplus is resold to the grid (negative price of energy cost).

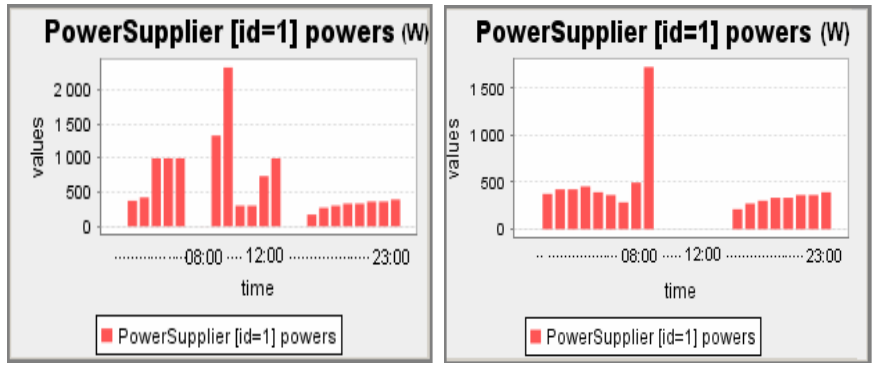




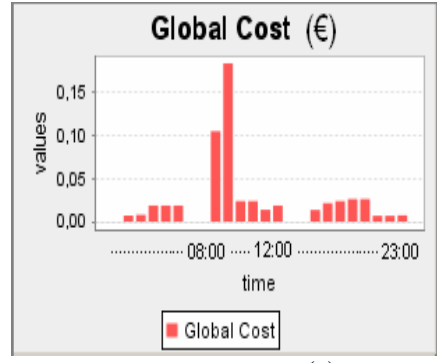

(a)

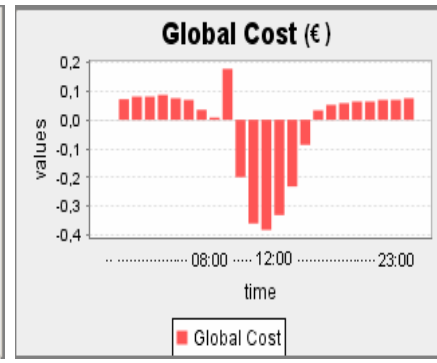

(b)
Fig 11: Power supplier and global cost of energy calculated by the EMS for tow cases: (a) without PV and (b) with Germany PV

As shown in "Fig.12-a", the set-point temperature changes during the day, that's why the consumption profile in the two cases is variable (see Fig.11 (a)).

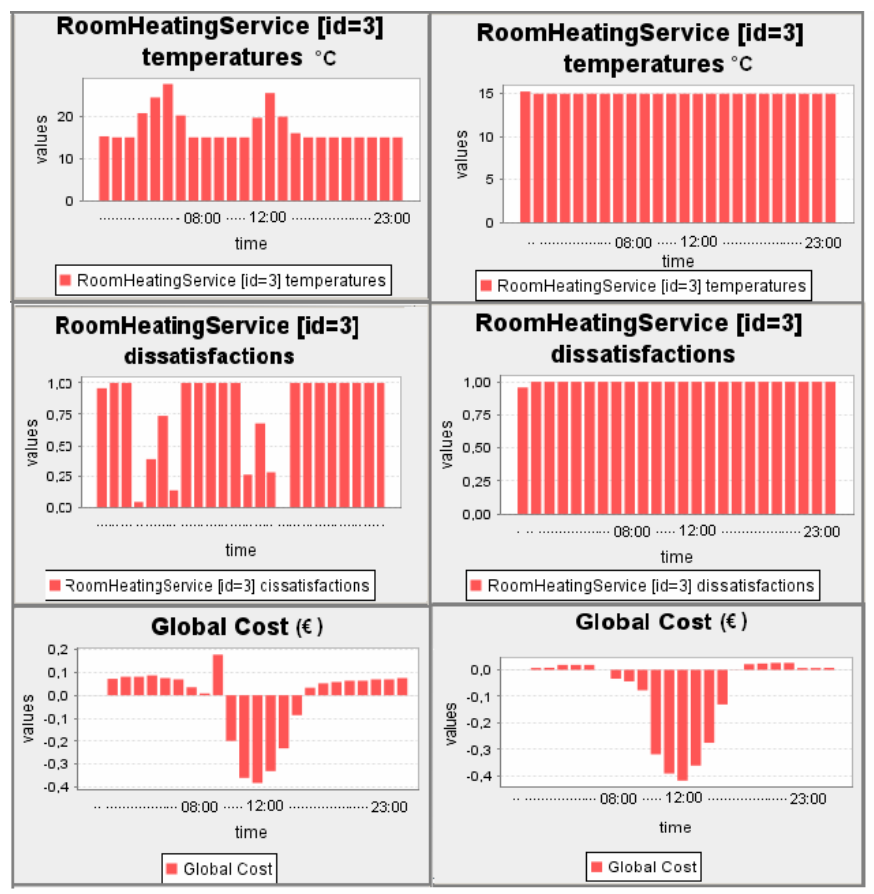

(a)

(b)

Fig 12: Cost and comfort criteria

The comfort criterion is based on the thermal sensation regarding the heating services and the offset services. In "Fig 12 -a", the comfort criterion has been favorized to give more importance to the comfort of the user than to the economic and ecological criteria. But the cost criterion is not neglected ; the start time of washing machine is shifted to avoid the period when the frid energy price is very high. This figure shows that the system favorizes the consumption of the heater during the Off-peak period by taking advantage of the cheaper price of the electricity to acheive the optimum temperature set point $\mathrm{T}_{\mathrm{opt}}=20^{\circ} \mathrm{C}$. However, in "Fig12-b", the comfort criterion has been deteriorated. The degradation is due to a decrease of the temperature in thermal environments. Tin $=15^{\circ} \mathrm{C}$, all the day. But, we note that the global cost is minimized compared to the firt scenario.

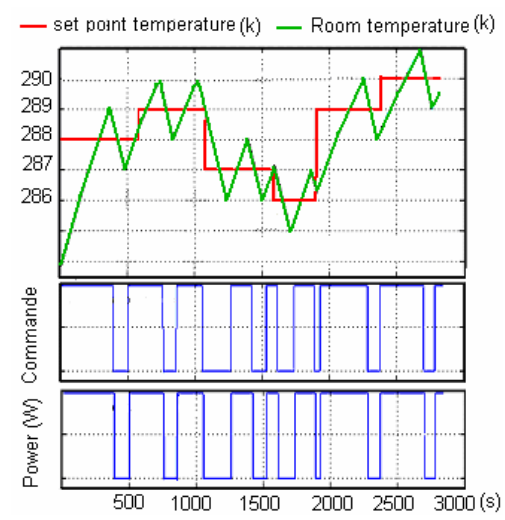

Fig 13: Local control and actual temperature of heating service.

The real time simulation results from (Host PC1 see "Fig3") during one hour are shown in "Fig.13". There is a local control ( \pm 1 Kelvin) of the simulation model that follows the EMS command (the red line).

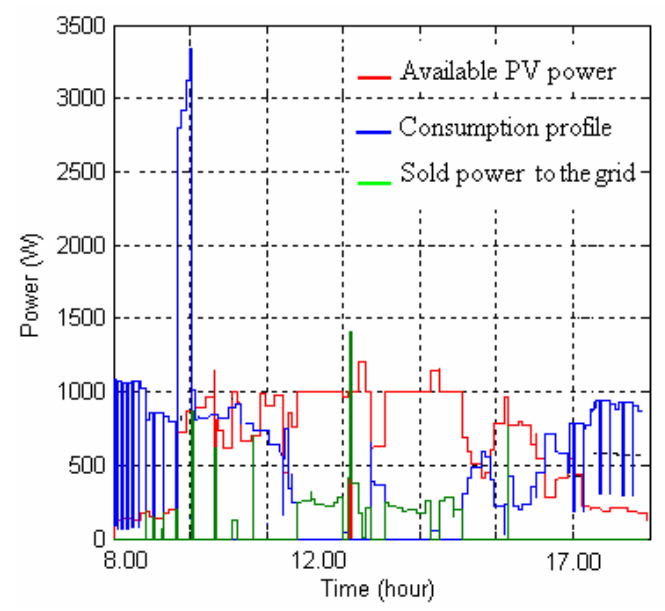

Fig 14: Real time simulation for the system during1 day.

Previous "Fig. (11 and 12)" show the solution given by the anticipative layer. But, the "Fig.14" is a real time simulation for all the systems (building simulation matlab connected to the EMS) during a day.

\section{CONCLUSION}

In this paper, an approach of Energy Management System in home automation has been presented. It has three layers: an equipment layer, with local and fast control mechanism, a reactive layer, which is triggered when energy constraints are violated, and an anticipative layer, which adjusts future setpoints of devices in order to tackle energy events that can be foreseen. This paper deals mainly, with an anticipation layer that allocates energy by taking into account predicted events.

This work proposes a solution to validate Energy Management System. The validation is obtained through realtime simulation.

The problem of energy management is a multi-criteria optimization problem whose criteria are contradictory between cost and comfort. A solution satisfying this two 
criteria has been presented and validated: It leads to the best compromise between criteria according to defined weights.

A case study has been presented. In this case, the optimal temperature setpoints for heating services have been computed. Furthermore, the best starting time for the washing machine has been determined.

The persepectives of this work will expand the validation of EMS with other loads such as lighting, cooking, oven, microwave ect., but also to improve the consideration of the impact of occupants

Realtime simulation for validation makes it possible hardware-in-the-loop validations to test real power sources and loads to check in the control can be actually handled by devices.

The successful home energy management yields various benefits. The management of load in electric power system benefits both power utilities and their customers and also saves environment from unnecessary pollution.

\section{ACKNOWLEDGMENT}

This paper has been supported by the French National National Research Agency ANR - Project: RéactivHome

\section{REFERENCES}

[1] Palensky, P., Posta, R., 1997. Demand side management in private home using lonworks. In : Proceedings.1997 IEEE International Workshop on Factory Communication Systems

[2] Wacks, K., 1993. The impact of home automation on power electronics. In : Applied Power Electronics Conference and Exposition. pp. 3 - 9.

[3] Paracha, Z.J.; Doulai, P.1998. Load management: techniques and methods in electric power system. IEEE Energy Management and Power Delivery, 1998. Proceedings of EMPD '98. 1998 International Conference on . Page(s): 213 - 217 vol.1

[4] Narasimhan, S. ; McIntyre, D. ; Wolff, F. ; Yu Zhou ; Weyer, D. Bhunia,S. 2010. A supply-demand model based scalable energy management system for improved energy utilization efficiency. The 2010 IEE Green Computing Conference, 2010 International, Page(s): $97-105$.

[5] Wacks, K., 1991. Utility load management using home automation. IEEE journal, Consumer Electronics, IEEE Transactionson Volume: 37 , Issue: 2

[6] Duy Long Ha, Stephane Ploix, Mireille Jacomino and Minh Hoang Le (2010). Home energy management problem: towards an optimal and robust solution. Energy Management, Francisco Macia Perez (Ed.), ISBN: 978-953-307-065-0, INTECH,

[7] Clastres C., Ha Pham, T.T., Wurtz, F., Bacha, S. (2010). Ancillary services and optimal household energy management with photovoltaic production. Energy, Vol. 35, $\mathrm{n}^{\circ}$ 1, pp. 55-64.

[8] Ha, D. L., Ploix, S., Zamai, E. \& Jacomino, M. 2006. Tabu search for the optimization of household energy consumption, The 2006 IEEE International Conference on Information Reuse and Integration IEEE IRI 2006: Heuristic Systems Engineering September 16-18, 2006, Waikoloa, Hawaii, USA

[9] S. Abras, Système domotique Multi-Agents pour la gestion de l'énergie dans l'habitat. Thèse de Doctorat - Institut National Polytechnique de Grenoble (INP Grenoble) Grenoble, Mai, 2009, chapitre 5 et 6 , page $61-129$

[10] Duy Ha, L. (2007). Un système avancé de gestion d'énergie dans le bâtiment pour coordonner production et consommation. Thèse de Doctorat - Institut National Polytechnique de Grenoble (INP Grenoble) Grenoble, Septembre, 2007.

[11] http://www.opal-rt.com/sites/default/files/rtlab brochure en.pdf.
[12] A. DAMIAN, A., VIRGONE, J., FRAISSE, G. Modélisation thermique d'un bâtiment monozone dans l'environnement TRNSYS. Bulletin Scientifique de l'UTCB (Université Technique de Construction de Bucarest), n³, 1997

[13] Missaoui R., Warkozek G., Bacha S., Stéphane.P. 2011. Real-Time Simulation For The Management Of Energy Flow In The Habitat. Electrimacs 2011, 6-8th June 2011, Cergy-Pontoise, France under revision

[14] M. Nathan. Building thermal performance analysis by using matlab/simulink. In Seventh International IBPSA Conference, Rio de Janeiro, Brazil, 2001.

[15] Kampf, J. H. et Robinson, D. (2006). A simplied thermal model to support analysis of urban resource flows. Energy and Building, InPress. (cité page 58).

[16] Missaoui R., Warkozek G., Bacha S., Stéphane.P. 2011. Energy Fluxes optimization for PV integrated Building. IEEE PES Trondheim PowerTech 201119 - 23 June. under revision. 